\title{
Beta $\mathrm{Ti}-45 \mathrm{Nb}$ and $\mathrm{Ti}-50 \mathrm{Nb}$ alloys produced by Powder Metallurgy for aerospace application
}

\author{
Martins, G.V. ${ }^{1,}$, , Silva, C.R.M. ${ }^{2, b}$, Nunes, C.A. ${ }^{3, c}$, Trava-Airoldi, V.J. ${ }^{1, d}$, \\ Borges Junior, L.A. ${ }^{4, e}$, Machado, J.P.B. ${ }^{1, f}$ \\ ${ }^{1}$ INPE, Av. dos Astronautas, 1.758, S. J. Campos - SP, CEP. 12245-970, Brazil \\ ${ }^{2}$ UnB, Asa Norte, Brasília - DF, CEP. 70910-900, Brazil \\ ${ }^{3}$ USP - EEL, Polo Urbo Industrial, Gleba AI-6, Lorena - SP, CEP. 12600-970, Brazil \\ ${ }^{4}$ UNIFOA, Av. Paulo E. A. Abrantes, 1.325, Volta Redonda - RJ, CEP. 27240-560,Brazil \\ agivmartins@yahoo.com.br, bcosmeroberto@gmail.com, ccnunes@demar.eel.usp.br, \\ vvladimir@las.inpe.br, ${ }^{\mathrm{e}}$ borges.jr@itelefonica.com.br, joaopaulo@las.inpe.br
}

Keywords: Ti-Nb alloy, powder metallurgy, aerospace and elastic modulus.

\begin{abstract}
Beta titanium alloys parts are used on advanced aerospace systems because of their high strength to weight ratio and excellent corrosion resistance. Production of powder metallurgy titanium alloys components may lead to a substantial reduction in the cost, compared to those produced by conventional cast and wrought processes, because additional working operations and material waste can be avoided. In this work, beta Ti- $45 \mathrm{Nb}$ and Ti$50 \mathrm{Nb}$ were produced by the blended elemental technique, followed by uniaxial and cold isostatic pressing with subsequent densification by sintering. Sintered samples were characterized for phase composition by XRD, microstructure by SEM, hardness by Vickers indentation, specific mass by the Archimedes method and elastic modulus by resonance ultrasound. The sintered samples presented only the beta phase, higher hardness and lower elastic modulus when compared to Ti6Al4V alloy and experimental specific mass value near theoretical specific mass. These characteristics are adequate for application on several aerospace parts.
\end{abstract}

\section{Introduction}

Comparing to ferrous and non-ferrous metallic materials, titanium alloys have various advantages such as high strength to weight ratio, good resistance to many corrosive environments and can be used over a wider range of temperatures. Their application in aerospace industry has been restricted because of high costs generated by the expensive raw materials, mechanical processing and machining operations [1]. Significant cost reductions can be obtained by vacuum hot pressing (VHP) and powder metallurgy (P/M) techniques by producing near net shapes and consequently minimizing material waste and machining time [2].

The first commercially significant $\beta$ titanium alloy, for aerospace industry, was Ti-13V$11 \mathrm{Cr}-3 \mathrm{~A} 1$, used extensively (wing and body skins, frames, longerons, ribs, rivets and landing gears) on the SR-71 "Blackbird" reconnaissance airplane. One of the key reasons for selection of Ti-13-11-3 was its thermal stability. In terms of tonnage, Ti-10V-2Fe-3Al is the most highly used of the $\beta$ Ti alloys with the production requirements of the Boeing 777 airplane [3]. Considering all $\mathrm{Ti}$ alloys, it is important to note that Ti6Al4V is the most widely produced and 
used alloy, so its chemical and physical properties are references for the next generation of alloys [4].

Still concerning aerospace application titanium and its alloys can also replace aluminum when the operating temperature exceeds about $130{ }^{\circ} \mathrm{C}$, which is the normal maximum operating temperature for conventional aluminum. These conditions exist, for example, in the nacelle and auxiliary power unity (APU) areas and wing anti-icing system for airframe structures. Steel and nickel-base alloys are obvious alternative, but they have a density about 1.7 times that of titanium [5].

In this paper it will be presented the development and characterization of both Ti- 45 wt. $\% \mathrm{Nb}(\mathrm{Ti}-45 \mathrm{Nb})$ and $\mathrm{Ti}-50 \mathrm{wt} \% \mathrm{Nb}(\mathrm{Ti}-50 \mathrm{Nb})$, using the blended elemental technique, comparing with $\mathrm{Ti}$ and its alloys properties, and showing its potential for application on aerospace industry.

\section{Experimental Procedure}

The blended elemental method followed by a sequence of uniaxial cold pressing, cold isostatic pressing and sintering was chosen for the preparation of the Ti- $45 \mathrm{Nb}$ and $\mathrm{Ti}-50 \mathrm{Nb}$ alloys. Both Niobium and Titanium powders were obtained by the hydride-dehydride (HDH) process. Niobium chips originated from a machining operation on a high purity Niobium ingot (Electron bean melted) were washed in water, acid pickled and dried in stove. These were submitted to hidrogenation treatment in electric resistance furnace at a temperature of $600^{\circ} \mathrm{C}$, under $0.15 \mathrm{MPa}$ of pure $\mathrm{H}_{2}$ and overcooled to room temperature. Titanium's sponges coming from the Kroll process were hydrogenized in vertical furnace, at $500{ }^{\circ} \mathrm{C}$ and $0.1 \mathrm{MPa}$ of pure $\mathrm{H}_{2}$. The hydrogenated powders were milled in a vibratory mill without protecting atmospheres. The dehydriding stage was carried out in dynamic vacuum conditions, at $800{ }^{\circ} \mathrm{C}$ for $\mathrm{Nb}$ and $550{ }^{\circ} \mathrm{C}$ for Ti. The starting powders were weighted with the desired composition and blended in a planetary mill, putting the mixture inside a closed plastic recipient with balls inside. After that, the powders were: cold uniaxially pressed, under pressure of $10 \mathrm{MPa}$, in cylindrical $15 \mathrm{~mm}$ dia-dies and encapsulated under vacuum in flexible rubber moulds for cold isostatically presseing (CIP) at $350 \mathrm{MPa}$ for $30 \mathrm{~s}$ in an isostatic press. The specimens were sintered at a temperature of $1700{ }^{\circ} \mathrm{C}$, in high vacuum, with a heating rate of $20{ }^{\circ} \mathrm{C} / \mathrm{min}$. On the nominal temperature, the sample were held at the chosen temperature for $2 \mathrm{~h}$ and then the furnace was cooled to room temperature. Microstructural analysis of the materials was performed in a LEO-ZEISS 1450 VP scanning electron microscope (SEM); and a Philips PW1380/80 X-ray diffractometer (XRD). The sample were hot mounted in resin, ground from \#180 to \#4000 SiC sandpaper and polished using OPS (colloidal silica - Struers) with oxalic acid. Etching was done by immersing the samples in a modified Kroll solution $(3 \mathrm{ml} \mathrm{HF}+6$ $\mathrm{ml} \mathrm{HNO} 3+100 \mathrm{ml} \mathrm{H} 2 \mathrm{O}$ ) for 10 seconds to reveal its microstructures. Microhardness tests were carried out in Micromet 2004 equipment, Buehler, with a load of $0.2 \mathrm{kgf}$. The density of the sintered sample was determined by the Archimedes method and the elastic modulus by resonance ultrasound.

\section{Results and Discussion}

Fig. 1 presents the SEM micrographs of the Ti-45Nb and Ti-50Nb alloys. One can observe, for both samples, the presence of few pores (round shape and black color), the grain boundary lines revealed after chemical etching and the existence of only one gray color tonality of the 
grains indicating a single-phase material. It was not observed, after sintering, unreacted $\mathrm{Nb}$ or Ti particles.
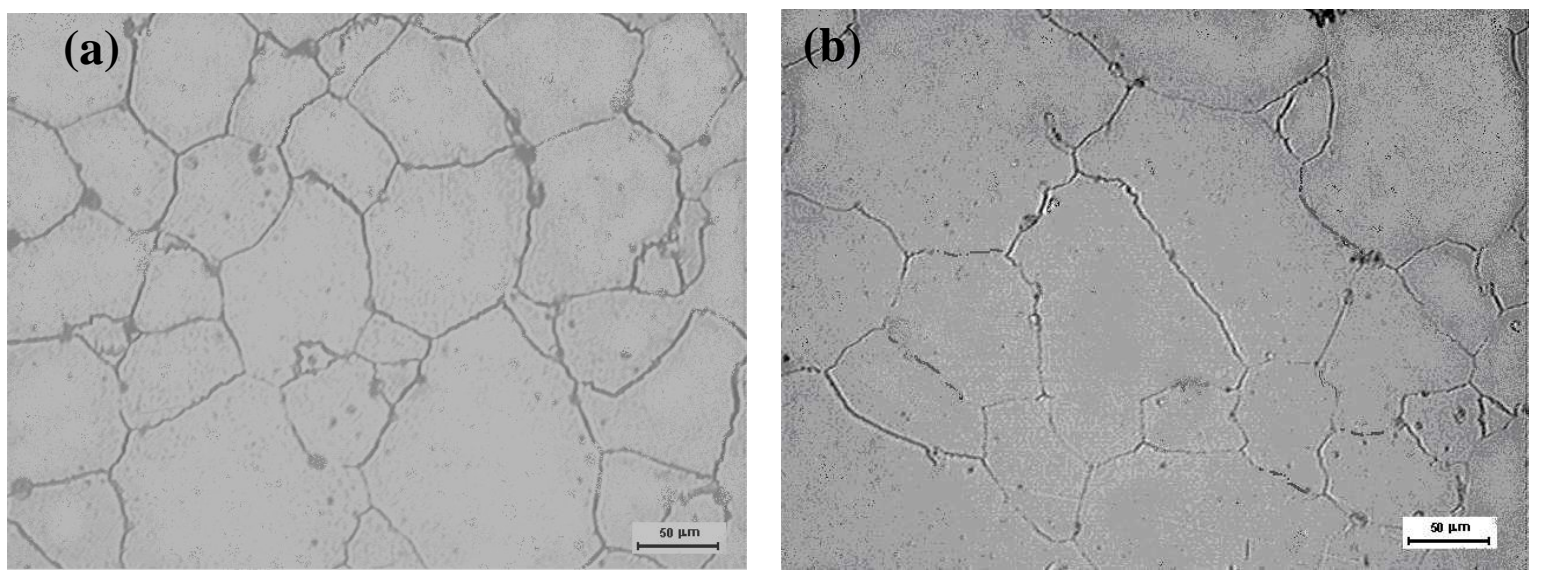

Fig. 1. Microstructure of the Ti-45Nb (a) and Ti-50Nb (b) alloys after sintering at $1700{ }^{\circ} \mathrm{C} / 2 \mathrm{~h}$.

The XRD analysis confirmed that both alloys are monophasics, with the presence of $\beta$ phase only (Fig. 2). This phase is characterized by its low Young modulus.

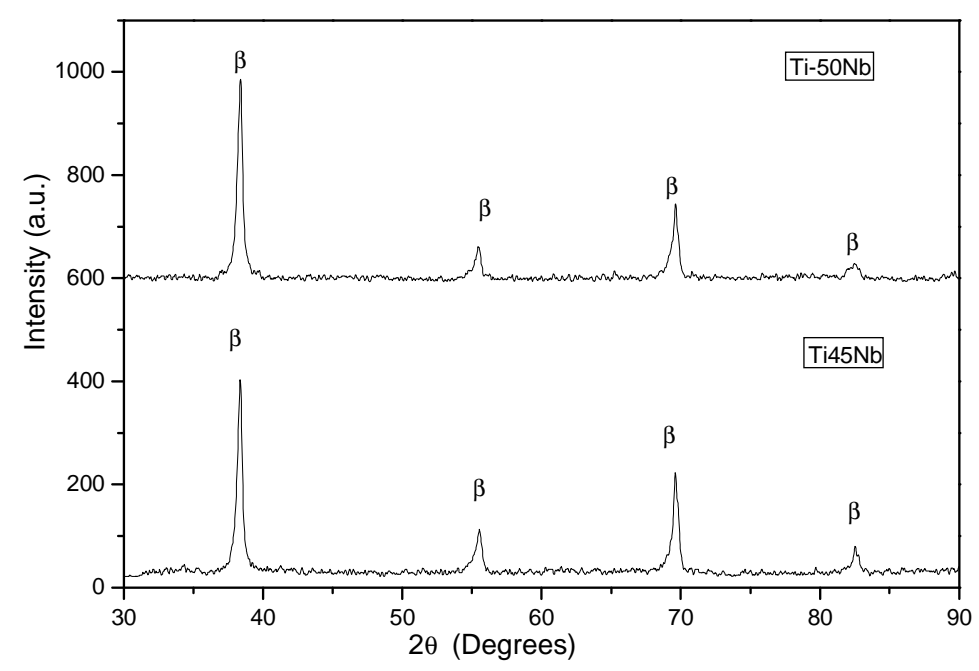

Fig. 2. XRD spectrum for sintered $\mathrm{Ti}-45 \mathrm{Nb}$ and $\mathrm{Ti}-50 \mathrm{Nb}$ samples.

It is very well know that a lower specific mass is desirable for aerospace application. Table 1 presents the theoretical specific mass, specific mass after sintering and relative density for $\mathrm{Ti}-45 \mathrm{Nb}, \mathrm{Ti}-50 \mathrm{Nb}$, pure titanium and Ti6Al4V. It can be seen that the theoretical specific mass of the alloys developed in this work have a specific mass approximately 1.3 times bigger than that of the Ti6Al4V alloy. Comparing with the values of the sintered samples this factor goes to 1.2, confirming that the specific mass is satisfactory for aerospace application.

The sintered alloys presented a high relative density mainly indicating that the pressing and sintering parameters are adequate. 
Table 1. Theoretical specific mass, specific mass after sintering and relative density for Ti$45 \mathrm{Nb}, \mathrm{Ti}-50 \mathrm{Nb}$, pure titanium and Ti6Al4V.

\begin{tabular}{cccc}
\hline Samples & $\begin{array}{c}\text { Theoretical } \\
\text { specific mass } \\
\left(\mathrm{g} / \mathrm{cm}^{3}\right)\end{array}$ & $\begin{array}{c}\text { Specific mass } \\
\text { after sintering } \\
\left(\mathrm{g} / \mathrm{cm}^{3}\right)\end{array}$ & $\begin{array}{c}\text { Relative } \\
\text { density } \\
(\%)\end{array}$ \\
\hline Ti-45Nb $\left(1700^{\circ} \mathrm{C}\right)$ & 5,73 & 5,41 & 93,71 \\
Ti-50Nb $\left(1700{ }^{\circ} \mathrm{C}\right)$ & 5,92 & 5,60 & 93,41 \\
Pure Ti ASTM F67 & 4,51 & - & - \\
Ti6Al4V ASTM F136 & 4,42 & - & - \\
\hline
\end{tabular}

Fig. 3 shows the Vickers hardness values for Ti-45Nb, Ti-50Nb, pure Ti, Ti6Al4V and INOX F138. It can be seen that both alloys, Ti-45Nb and Ti50Nb, presented a slightly higher hardness comparing to the other materials. This fact assures a slightly better tribological performance of these $\mathrm{Ti}-\mathrm{Nb}$ alloys

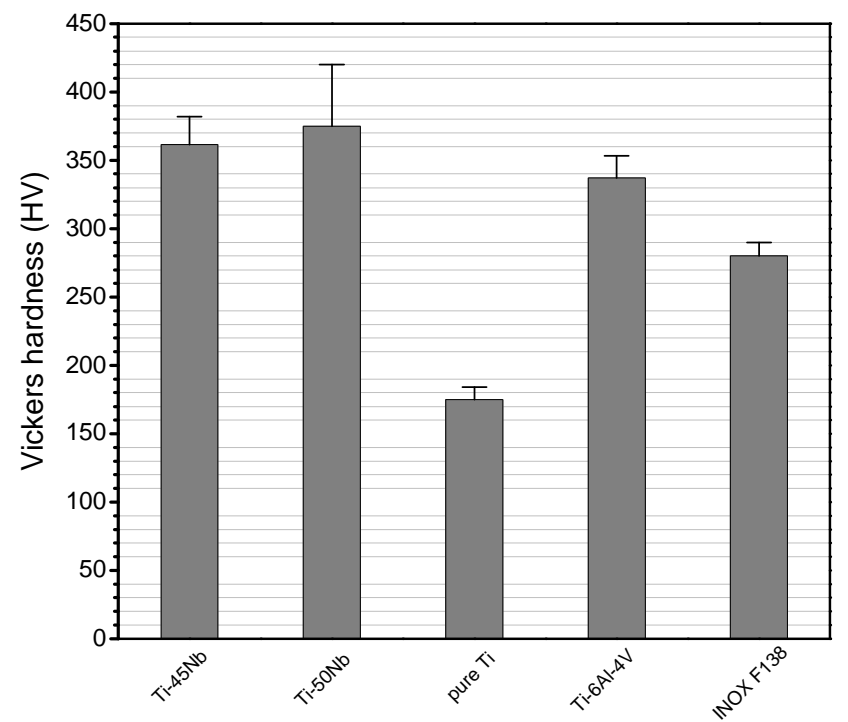

Fig. 3. Vickers hardness values for Ti-45Nb, Ti-50Nb, pure Ti, Ti6Al4V and INOX F138.

There are lots of applications, in the aerospace field, that require flexible metallic materials. Fig. 4 presents the elasticity modulus for Ti-45Nb, Ti-50Nb, pure Ti, Ti6Al4V and INOX F138. One can observe that both Ti-Nb alloys exhibited the lower modulus. Their Young modulus are approximately 1.4 times lower compared to Ti6Al4V modulus. 


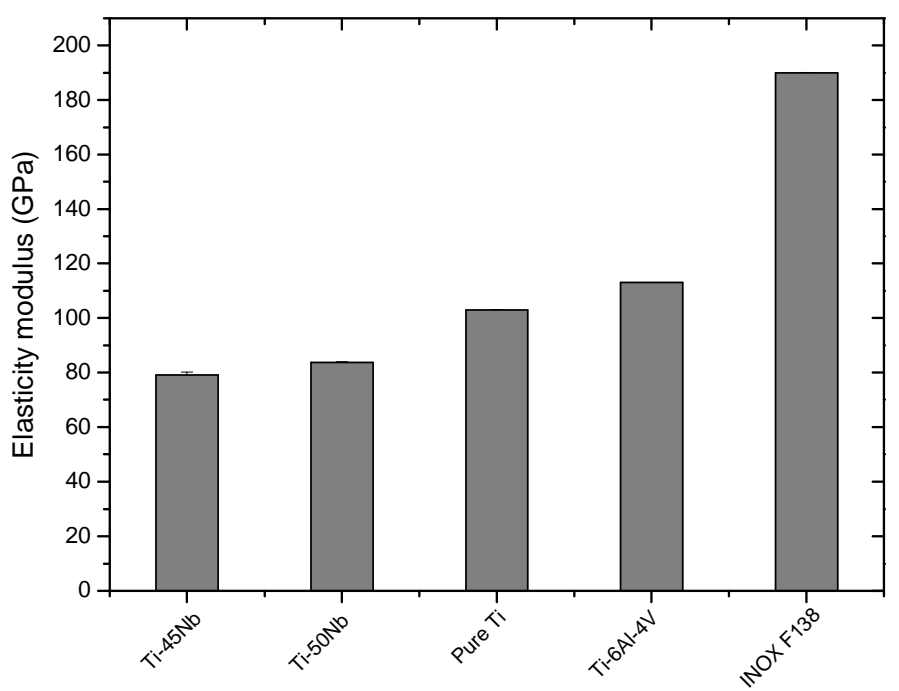

Fig. 4. Elasticity modulus for Ti-45Nb, Ti-50Nb, pure Ti, Ti6Al4V and INOX F138.

\section{Conclusions}

From this work it can be concluded that it was possible to develop Ti-Nb alloys, using the blended elemental technique, with satisfactory characteristics for aerospace application.

The parameters for the stages of powder obtaining, pressing and sintering could be well adjusted to obtain $\mathrm{Ti}-\mathrm{Nb}$ alloys with a single $\beta$ phase, high relative density, higher hardness and lower elasticity modulus when compared to Ti6Al4V alloy.

\section{Acknowledgements}

The authors thank the financial support of the Brazilian research financing institutions CNPq and FAPESP, and the technical support of CTA and UNICAMP.

\section{References}

[1] P. Allen: Adv. Matter. Process., Vol. 10 (1996), p. 35-37.

[2] P.J. Andersen, N.E. Alber, E.L. Thellmann: Precis. Met., Vol. 104 (1980), p. 34-41.

[3] R.R. Boyer: Materials Science\&Engineering A, Vol. A213 (1996), p. 103-114.

[4] F.H. Froes, D. Eylon: Powder metallurgy of titanium alloys- A review. Powder Metallurgy International. 1985; 17(4):163-167.

[5] P.J. Andersen, N.E. Alber, E.L. Thellmann: P/M Titanium reduces aerospace components costs. Precision Metals. 1980; 104:34-41. 